\title{
Prioritizing sleep for healthy work schedules
}

\author{
Masaya Takahashi
}

\begin{abstract}
Good sleep is advantageous to the quality of life. Sleep-related benefits are particularly helpful for the working class, since poor or inadequate amounts of sleep degrade work productivity and overall health. This review paper explores the essential role of sleep in healthy work schedules and primarily focuses on the timing of sleep in relation to the work period (that is, before, during and after work). Data from laboratory, field and modeling studies indicate that consistent amounts of sleep prior to work are fundamental to improved performance and alertness in the workplace. In addition, planned naps taken during work maintain appropriate levels of waking function for both daytime and night-time work. Clearly, sufficient sleep after work is vital in promoting recovery from fatigue. Recent data also suggest that the time interval between shifts should be adjusted according to the biological timing of sleep. Although sleep is more likely to be replaced by job and other activities in the real life, research shows that it is worthwhile to revise the work schedules in order to optimize sleep before, sometime during and after the work period. Therefore, we suggest establishing work-sleep balance, similar to work-life balance, as a principle for designing and improving work schedules.
\end{abstract}

Keywords: Alertness, napping, productivity, recovery, sleep

\section{Introduction}

Advances in sleep research have produced a considerable amount of data regarding the role of sleep in all areas of life, including the workforce. Working individuals account for approximately half of the population in most countries, which emphasizes the significance of sleep for this particular group. At a worker level, inadequate sleep leads to a wide range of health disorders [1]. Also, sleep problems are associated with short- and long-term sickness leave [2] and further interfere with return to work following these absences $[3,4]$. In the long run, poor sleep causes work disability [4] and early retirement [5]. Furthermore, disrupted sleep dosedependently increases the risk of all-cause mortality in working men [6]. In reference to cause-specific mortality, severely disturbed sleep may be associated with a greater suicide risk, even after accounting for depressive symptoms [6]. This finding is highly relevant to the situations in Japan, with over 30,000 people committing suicide every year since 1998 [7]. Sleep problems are also a safety concern because they are associated with

Correspondence: takaham@h.jniosh.go.jp

National Institute of Occupational Safety and Health, 6-21-1, Nagao, Tama-ku, Kawasaki 214-8585, Japan occupational injuries, as shown in both cross-sectional and prospective studies $[8,9]$.

We believe it is important to address sleep-related occupational hazards from not only an individual perspective, but from a workplace perspective. At the workplace level, recent findings highlight the economic burden caused by employees with insufficient and/or poor sleep [10-12]. Although many differences exist among studies, sleep-related costs in the workforce are within a similar monetary range of approximately a few thousand dollars per person per year [10-12]. Importantly, due to the significant costs and the large number of workers affected, employers experience substantial economic damage from sleep-related problems.

Despite the clear disadvantages as listed above, the value of sleep has been somehow neglected. The decline in interest among occupational safety and health experts may occur because they view sleep as a 'private activity' outside of work. Consequently, the attitude towards sleep contrasts with the attitude towards work hours and stressors, even though both are critical to the quality of work.

The present review explores the essential role of sleep in healthy work schedules. This paper particularly focuses on when workers sleep, including before and 
after an assigned working period, and napping during the work shift.

Sleep before work: preparation for enhanced productivity Employees have the responsibility to be at their mental and physical best during a work shift. Achieving adequate amounts of sleep prior to work is a key factor contributing to productivity. In this context, the prior sleep wake model proposed by Dawson and McCulloch provides a simple, yet effective framework [13]. This model requires a certain minimum duration $(\mathrm{X}$ and $\mathrm{Y}$ hours, respectively) of sleep during the 24-hour and 48hour period prior to work, in order to prevent errors and accidents during wakefulness from awakening to end of work. Currently, $\mathrm{X}$ and $\mathrm{Y}$ are assumed to be 5 and 12 hours, respectively.

The validity of the proposed model has been tested across multiple work settings. For example, fatiguerelated accidents by truck drivers were accurately predicted by $\mathrm{X}=6.5$ and $\mathrm{Y}=8$ hours [14]. Data among train industry employees (for example, train drivers, controllers and guards) showed that extreme tiredness or exhaustion was significantly associated with sleep duration 24 hours prior to work, shift length, night shifts and workload, and that such symptoms were assumed to be reduced by $12 \%$ if the sleep was increased by one hour during that 24-hour period [15]. In airline crews, poor operational performance and increased errors were significantly associated with less than 6 hours of sleep in the 24 hours prior to work [16]. Similarly, miners who took less than 6 hours of sleep in the prior 24-hour period performed a psychomotor vigilance task (PVT) significantly slower than miners who had adequate sleep [17]. We also used the prior sleep wake model to analyze truck driver data and found that drowsy driving and/or motor vehicle crashes increased when drivers had 5 or fewer hours of sleep in the 24-hour period prior to the start of driving (Figure 1) [18].

Many workers experience chronic partial sleep deprivation over weekdays. Experimental evidence indicates that repeated partial sleep deprivation, even achieving 5 to 6 hours of night's sleep, causes a gradual impairment in neurobehavioral performance each day $[19,20]$. Extending sleep duration prior to partial sleep deprivation may counteract the subsequent impairments in performance. Indeed, a recent study showed that 10-hour time in bed (TIB) (approximately 8-hour total sleep time [TST]) for one week prior to seven days of sleep restriction ( 3 hours per night) yielded better PVT performance and electroencephalogram-defined alertness than spending 7-hours TIB (approximately 6-hour TST) the week before sleep restriction [21]. Moreover, the aforementioned sleep extension facilitated recovery in performance and alertness following sleep restriction.

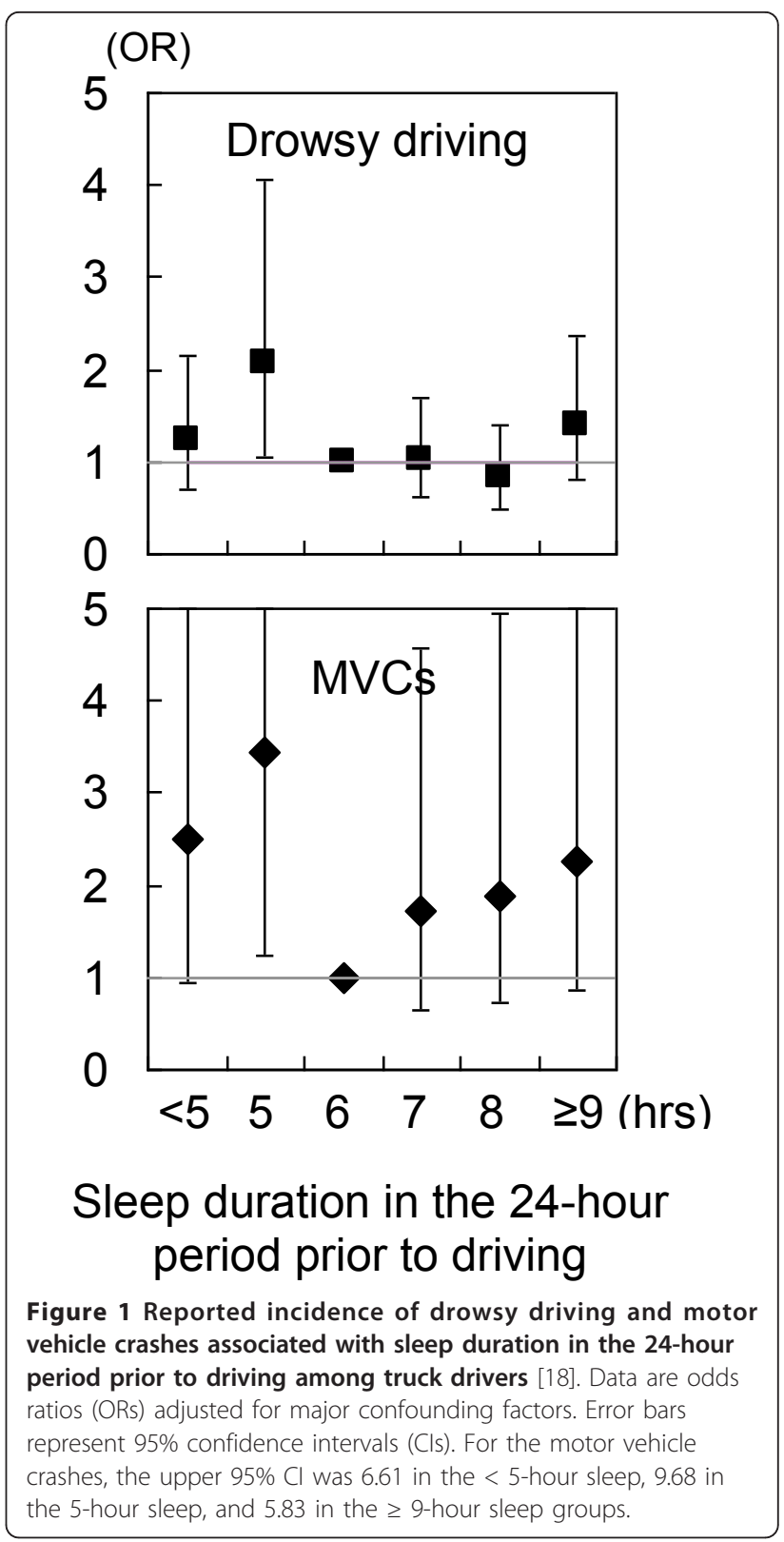

These findings suggest that banking extra sleep may be an effective coping strategy to ensure work performance and to improve the recovery when one anticipates a period of by chronic sleep deprivation.

Taken together, research demonstrates that acquiring an appropriate amount of sleep is a fundamental component to work productivity. We are not allowed to go to work while intoxicated; physiologically, skipping sleep has similar influences on the brain and body as drinking alcohol [22]. Consequently, we should not be allowed to work when we are sleep deprived. More attention should be directed to achieving appropriate and sufficient amounts of sleep prior to one's work shift. 


\section{Naps during work: maintenance of on-the-job performance}

Generally, employees are not entitled to take naps during their work periods. Napping is often confused with dosing off, which tends to be viewed as a counterproductive behavior. However, planned naps, if taken during working hours, are recognized as a promising technique in maintaining job performance and alertness [23-26]. Particularly, a brief (that is, 15 to 20 minutes) nap improves waking function $[23,27,28]$ and is ideal for employees, given the limited opportunity for napping in the workplace. Recent neuropsychological research supports this idea and has indicated that the nap-related gains in learning and memory may be potential mechanisms for improving cognitive function $[29,30]$.

In addition to the neurobehavioral benefits, planned napping may have favorable impacts on worker health. Based on results from a cohort study of over 23,000 participants, men who took 30-minute naps occasionally or napped at least three times per week showed a $50 \%$ decrease in their risk of coronary-related mortality (hazard ratio $0.51,95 \%$ confidence interval 0.32 to 0.83 ) [31]. Interestingly, this association was stronger for working men at enrollment (hazard ratio 0.36 , 95\% confidence interval 0.16 to 0.77 ) than for non-working men at enrollment (hazard ratio 0.64, 95\% confidence interval 0.33 to 1.21 ). Although the specific underlying mechanisms for these findings remain unclear, several immunological studies have revealed that while one night's sleep deprivation increased a proinflammatory cytokine (IL-6), a 2 -hour nap ( 2 p.m. to 4 p.m.) significantly reduced this effect. Moreover, the IL-6 level continually decreased following the nap period [32]. Similarly, sleep restriction of only 2 hours a night decreased immunological parameters, while the addition of a 30-minute daytime nap facilitated immunological recovery [33].

Appropriate use of napping is thought to be more beneficial for night and shift workers [23]. Indeed, when a nap schedule was integrated into the work shift of medical interns, those that napped slept longer while on-call and experienced less fatigue compared to interns that did not have a nap schedule [34]. Concurrently, research with health care workers showed that a $30-$ minute opportunity for napping in the middle of a night shift (2 a.m. to 3 a.m.) improved PVT performance and subjective sleepiness compared with no nap [35]. Findings from qualitative research with hospital nurses suggest that naps prove restorative during night shifts and that naps are necessary to achieve a high quality of care [36]. Many health care professionals who work at night and shift-work suffer from musculoskeletal disorders. Recent findings among nursing home caregivers indicate that taking a nap at least once every two night shifts was significantly associated with reduced pain in the neck, arm and leg, though not low back pain (Figure 2) [37]. These data imply that protecting the time for night-shift napping may also be effective in preventing work-related musculoskeletal injuries.

Importantly, naps are beneficial for a variety of workers, in addition to those in the health care industry. That is, international airline pilots take in-flight naps according to their perceived level of fatigue, which reiterates the use of naps as a preventive measure [38]. In addition, night shift air traffic controllers given a 40minute nap opportunity displayed better PVT performance and objective measures of alertness compared to controllers in the no-nap condition [39]. The similar favorable effects of a nap have been recognized for car driving [40].

In recent years, there has been a growing interest in the possible link between shift work, night shifts in particular, and cancer [41]. This concern is corroborated by the fact that the International Agency for Research on Cancer categorized 'shift work that involves circadian disruption' as probably carcinogenic to humans (Group 2A) [42]. Exposure to environmental light during the night shift suppresses melatonin, which is thought to be responsible for an increased cancer risk [43,44]. If so, taking a night-shift nap in a darkened room may exert a protective role against cancer through the reduction in light exposure; however, this hypothesis has yet to be examined.

The above arguments support the active use of naps during daytime and shift work periods. Sleep inertia (SI), transient decreases in performance and alertness that occur immediately after awakening, is sometimes regarded as a barrier to worksite napping [36]. However, we are able to minimize the negative effects of SI by providing either additional time after the nap, or by adjusting the nap duration, in order to restore the central nervous system function [45]. Therefore, although the effects of SI cannot be ignored, the value of on-thejob napping is important to overall function and should be considered in the workplace.

\section{Sleep after work: recovering from fatigue}

It is undisputable that sleep plays a vital role in one's recovery following a work period [46]. Chronic partial sleep deprivation studies emphasize the need for adequate sleep each and every night $[19,20]$. Unfortunately, the reality is that work and other activities are often completed at the expense of sleep. Several worksites in Japan have implemented a 'no-overtime day' in the middle of the week (for example, on Wednesday). Nevertheless, no empirical data are available regarding its effects on health, sleep or performance.

As it may be difficult to get adequate sleep every night, the second best opportunity for taking a sufficient 

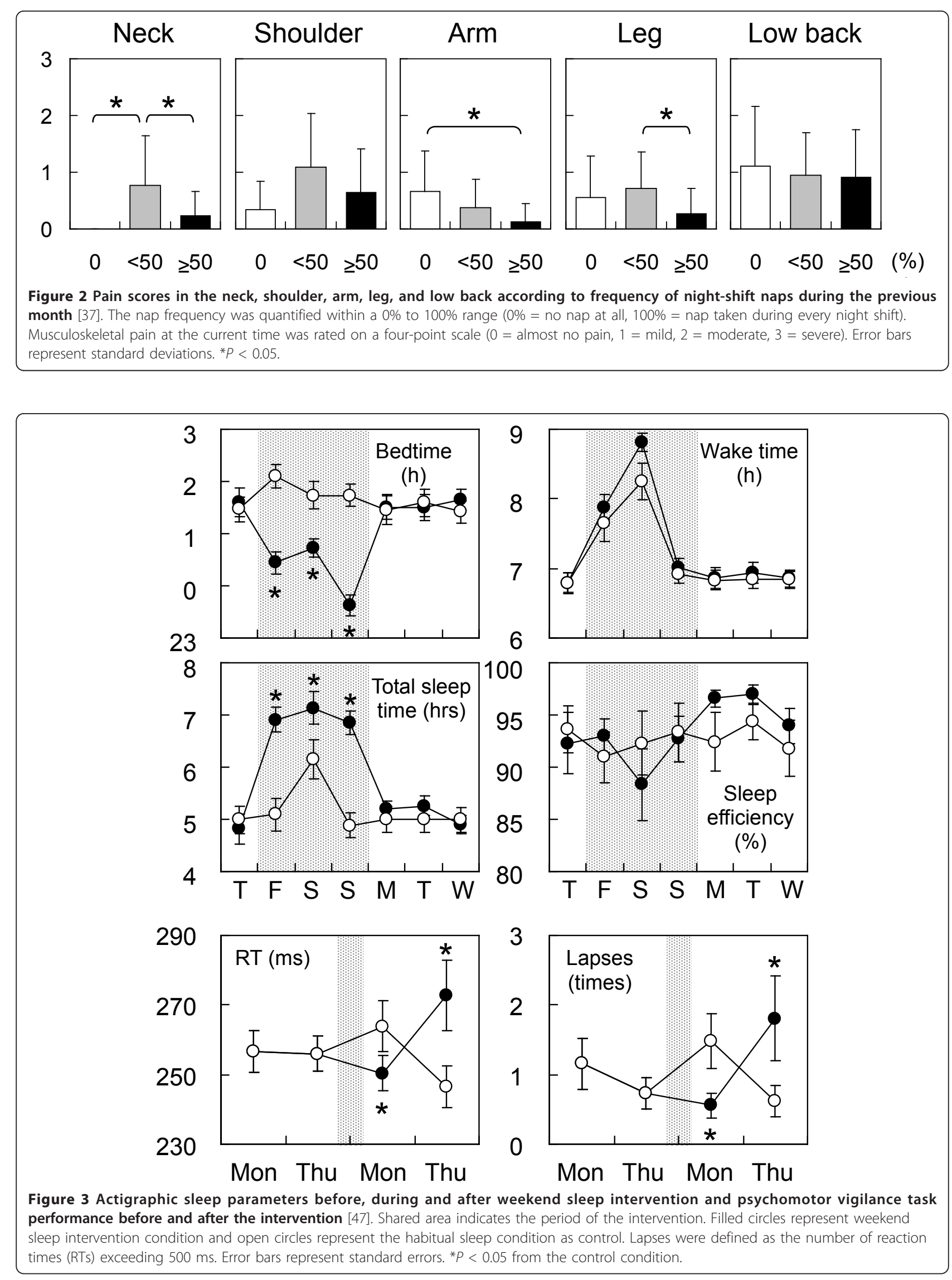
sleep may be on weekends. We tested the hypothesis that extended sleep during weekends would improve performance and alertness during the subsequent weekdays in daytime workers, specifically in those with habitually limited sleep (6 hours or less) [47]. One concern related to sleep extension on weekends is the 'BlueMonday effects', which is the impaired waking function during the first half of the subsequent week due to delays in circadian phase by sleeping in on the weekend [48]. To minimize these effects, participants in the intervention condition were instructed to stay in bed for $\geq 8$ hours between 10 p.m. and 9 a.m. and were prohibited from taking a daytime nap on weekends (Friday, Saturday and Sunday). Participants in the control condition were asked to keep their normal weekend sleep-wake pattern.

As depicted in Figure 3 (bedtime, wake time and TST), participants successfully adhered to the study, with the high quality of sleep measured by sleep efficiency. As expected, PVT performance on the Monday following the intervention condition was significantly better than the performance in the control condition. Interestingly, the opposite pattern was observed on Thursday. The explanations for these results are not yet clear, but an important factor may be the return to the habitual shorter sleep duration (approximately 5 hours TST) during the post-intervention week. In other words, the benefits of weekend sleep extension might have been maintained, if the participants had continued to achieve sufficient sleep during the week.

Particular care needs to be given to post-shift night sleep in order to support optimal recovery [49]. A long interval from a shift to the next shift is thus required. This feature may be critical to recovery, as sleep and health indicators have improved with the change from a fast, forward-rotating three-shift schedule (two days on each shift followed by four days off) to a slow, backward-rotating schedule with intermediate days off between shifts (three days on each shift followed by three days off prior to the next shift) [50].

Another important variable to consider is the individual differences in response to displacement of sleep disruption or sleep restriction [51,52]. Preliminary results assessing sleep recovery following four successive night shifts showed that there are at least four types of recovery: rapid, slow, pseudo and incomplete types (Figure 4) [53]. The recovery types were not associated with morningness-eveningness, the quality of daytime sleep during the night shift period, PVT performance or subjective sleepiness during the simulated night shifts. Instead, the inter-individual differences were associated with the participants' sleep habits, more specifically the timing of sleep (bedtime and the variability of wake time).

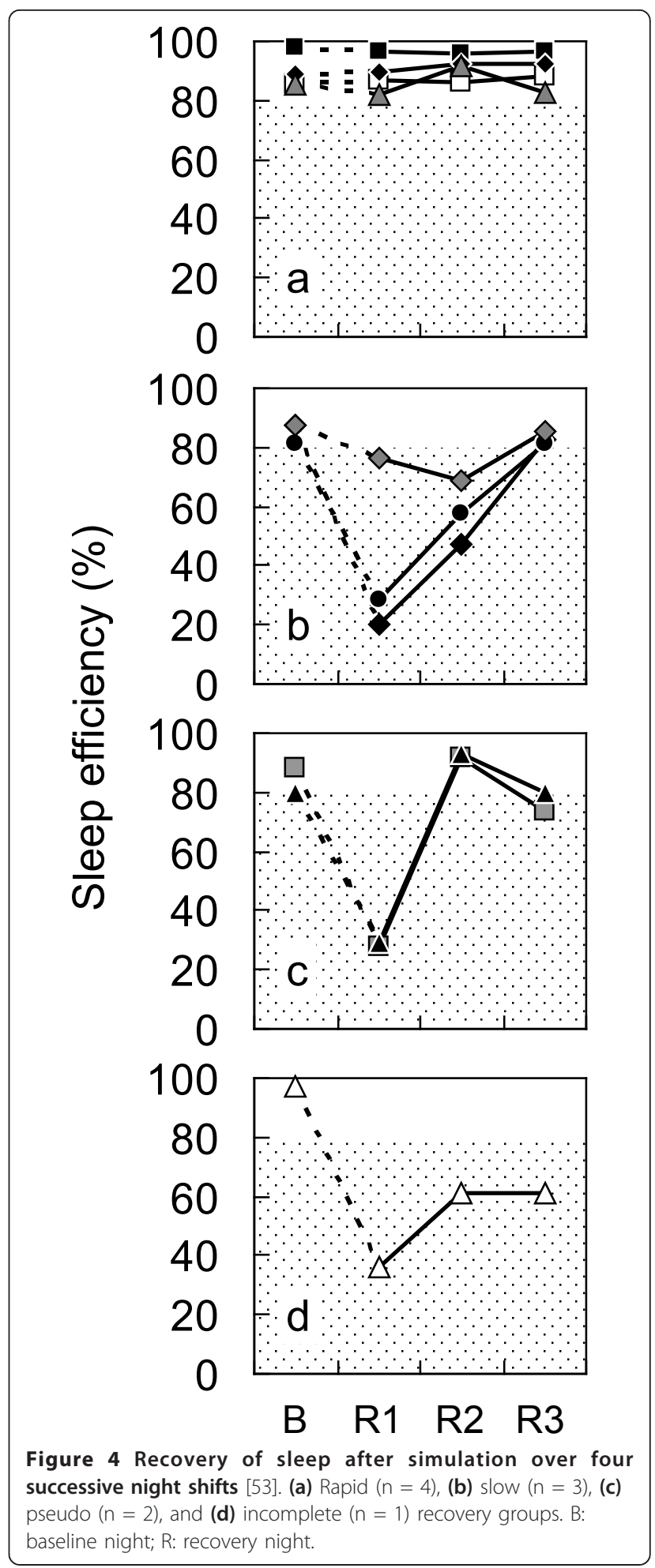

The latest findings demonstrate that not only is the length of shift interval (or days off) important, but that circadian timing should also be considered [54]. The same interval length between shifts does not necessarily exert the same recuperative power in regards to the 
time of day when the shift interval occurs. Although the current principles of shift work and working time recommend a certain length of rest (for example, 11 successive hours) $[55,56]$, additional revisions can be made to accommodate the circadian viewpoint [49].

In summary, work schedules should be designed to incorporate a sufficient time interval after every work period to promote sleep recovery. Moreover, the timing and duration of the rest interval need to be adjusted to account for shift requirements and circadian rhythms in order to ensure optimal recuperation.

\section{Future directions}

In a perfect world, employees would be very well prepared for demanding schedules such as shift work and long work hours. However, even in this ideal view, it is likely that some portion of employees will still experience health risks. The important point is to detect suboptimal health conditions and then to take appropriate action. In this regard, assessing sleep and alertness may provide useful information. In the previous study, nuclear power plant operators who displayed poor adaptation to their assigned work shift showed elevated sleep disturbances across sleep periods and unfavorable results on various outcomes compared to operators in the well-adapted group (Table 1) [57]. Moreover, pooradaptors reported decreased alertness during shifts, especially night shifts, compared to their well-adapted colleagues (Figure 5).

Physiologically, melatonin (for example, dim light melatonin onset) and body temperature may become candidates for health evaluations assessing the response to work schedules. These parameters, however, are easily masked by environmental conditions [58]. Additionally, it is quite difficult to establish normal levels under continuously perturbed work, sleep and light-dark cycle. In contrast, profiling clock genes is expected to be a breakthrough method for assessing work schedule-related damages to health $[59,60]$. More research is needed to determine its validity and feasibility.

Given the large variability in recent work schedules, biomathematical modeling may be a valuable tool to predict how sleep and performance are maintained $[58,61]$. Enhanced communication and collaboration is

Table 1 Sleep, health, and job outcomes for groups of nuclear power plant operators that perceive good or poor adaptation to shift work [57]

\begin{tabular}{|c|c|c|c|c|c|}
\hline & \multicolumn{4}{|c|}{ Perceived adaptation } & \multirow{3}{*}{$P^{\mathrm{a}}$} \\
\hline & \multicolumn{2}{|c|}{ Good $(n=250)$} & \multicolumn{2}{|c|}{ Poor $(n=358)$} & \\
\hline & Mean & (SD) & Mean & (SD) & \\
\hline Fit to job content (\%) & 80.3 & $(13.0)$ & 59.4 & (19.6) & $<0.001$ \\
\hline Eveningness (currently) & 3.7 & $(1.0)$ & 3.2 & $(1.1)$ & $<0.001$ \\
\hline Social and family disruption & 16.1 & $(6.4)$ & 20.0 & $(5.6)$ & $<0.001$ \\
\hline Chronic fatigue & 89.5 & $(21.9)$ & 103.7 & (20.9) & $<0.001$ \\
\hline Shift system advantages & 5.4 & $(2.1)$ & 5.0 & $(1.7)$ & 0.023 \\
\hline Shift work locus of control & 107.2 & $(15.2)$ & 99.1 & $(16.1)$ & $<0.001$ \\
\hline Psychological wellbeing (GHQ-12) & 11.6 & $(3.5)$ & 13.6 & $(4.2)$ & $<0.001$ \\
\hline Daytime sleepiness (ESS) & 6.7 & $(2.8)$ & 7.1 & $(2.9)$ & 0.033 \\
\hline \multicolumn{6}{|l|}{ Sleep disturbance } \\
\hline Day shift 1 & 20.8 & $(6.2)$ & 22.3 & $(6.0)$ & 0.002 \\
\hline Day shift 2 & 20.8 & (5.9) & 22.2 & $(5.7)$ & 0.005 \\
\hline Afternoon shift & 17.6 & (5.9) & 19.3 & $(5.9)$ & 0.007 \\
\hline \multicolumn{6}{|l|}{ Night shift 1} \\
\hline between afternoon shift and night shift 1 (night) & 17.8 & $(6.2)$ & 19.5 & $(6.1)$ & 0.004 \\
\hline Before night shift 1 (daytime) & 22.8 & $(7.5)$ & 27.7 & $(6.8)$ & $<0.001$ \\
\hline \multicolumn{6}{|l|}{ Night shift 2} \\
\hline between night shift 1 and night shift 2 (daytime) & 22.7 & $(7.2)$ & 26.3 & $(7.4)$ & $<0.001$ \\
\hline after night shift 2 (daytime) & 22.0 & (6.3) & 24.9 & $(6.7)$ & $<0.001$ \\
\hline on the first day off (night) & 16.7 & $(6.3)$ & 18.8 & $(6.3)$ & 0.001 \\
\hline \multicolumn{6}{|l|}{ Napping during night shifts (hours) } \\
\hline Night shift 1 & 1.5 & $(0.9)$ & 1.3 & $(0.9)$ & 0.001 \\
\hline Night shift 2 & 1.8 & $(1.5)$ & 1.5 & $(1.3)$ & 0.001 \\
\hline
\end{tabular}

${ }^{a}$ Adjusted for age. Fit to job content was assessed by the question 'How well do you fit the current job content?' on a 0 to $100 \%$ scale in $10 \%$ units. Higher scores for sleep disturbance indicate more disturbances. ESS: Epworth Sleepiness Scale; GHQ-12: 12-item General Health Questionnaire. 


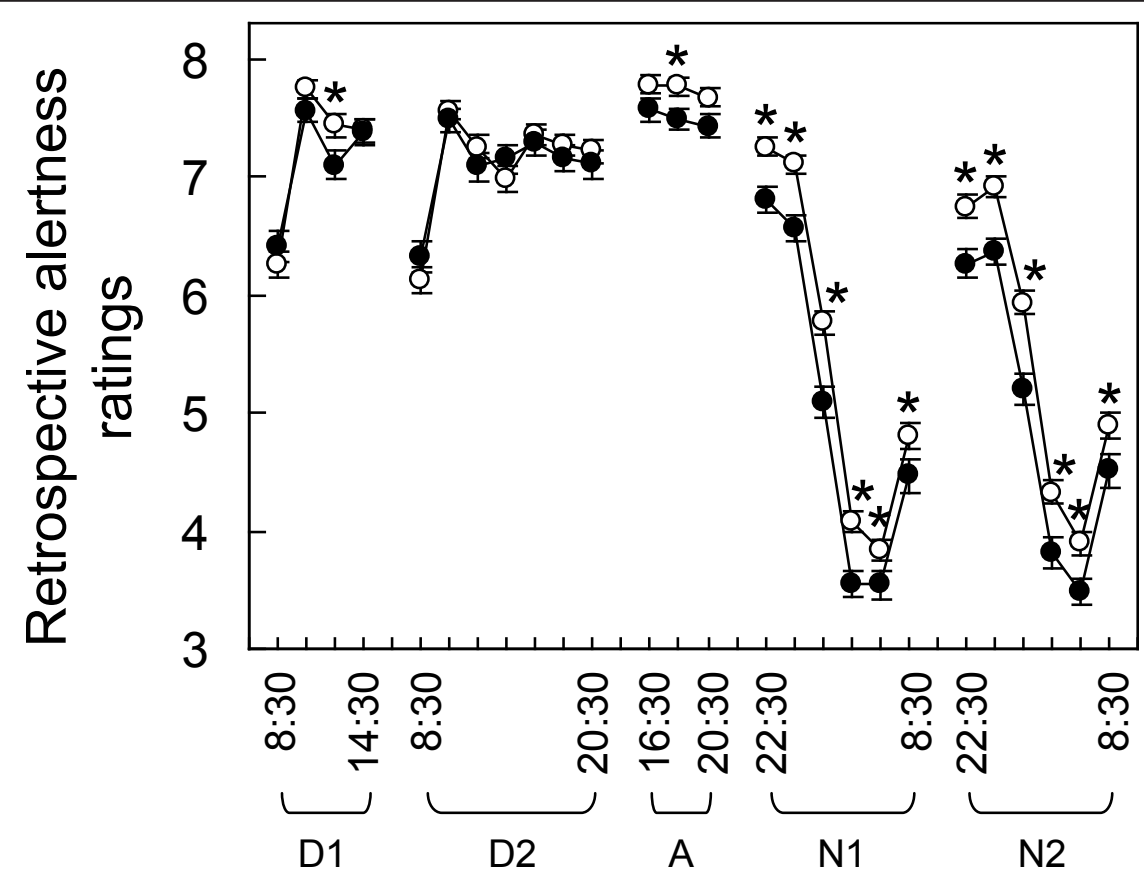

Figure 5 Retrospectively rated alertness during each shift for operators reporting good (open circle) and poor (filled circle) perception of adaptation to shift work [57]. Higher scores indicate greater alertness: 7 = alert, 5 = neither alert nor sleepy, $3=$ sleepy (but not fighting sleep). Error bars represent standard errors. ${ }^{*} P<0.05$ (adjusted for age). A: afternoon shift; D: day shift; N: night shift.

needed between laboratory experiments and field studies to address the improvements and sophistication of the given models.

Finally, a large portion of sleep research has focused on the negative consequences of sleep disruption or restriction, such as impaired health and decreased job performance. To better disseminate the importance of sleep to employers and many stakeholders, research should focus more on the benefits of obtaining adequate sleep. Several lines of evidence did demonstrate that sleep should be optimized to make employees more healthy and creative [62-64].

\section{Conclusions}

Numerous research findings so far support the idea that that inadequate sleep is detrimental to both workers and the workplaces. Although further studies are needed to establish a specific causal relationship, action should be taken to protect employees, employers and stakeholders against sleep-related disadvantages. Work schedules affect every aspect of working life; improper scheduling may result in sleep restriction and/or disturbance, which could then lead to dire consequences for everyone. However, work schedules can be modified to ensure that workers are able to get optimal levels of sleep before, sometime during, and after the work period. Although work-life balance has received much attention, here we propose that work-sleep balance, through the creation of healthy work schedules, is equally essential for improved working life.

\section{Acknowledgements}

This work was supported partly by the National Institute of Occupational Safety and Health, Japan (P20-05).

\section{Competing interests}

The authors declare that they have no competing interests.

Received: 8 February 2012 Accepted: 13 March 2012

Published: 13 March 2012

\section{References}

1. Committee on Sleep Medicine and Research, Institute of Medicine of the National Academy of Sciences: Sleep disorders and sleep deprivation: An unmet public health problem Washington, D.C.: National Academies Press; 2006.

2. Rahkonen O, Lallukka T, Kronholm E, Vahtera J, Lahelma E, Laaksonen M: Sleep problems and sickness absence among middle-aged employees. Scand J Work Environ Health 2011.

3. Åkerstedt T, Kecklund G, Selen J: Disturbed sleep and fatigue as predictors of return from long-term sickness absence. Ind Health 2010, 48:209-214.

4. Salo P, Oksanen T, Sivertsen B, Hall M, Pentti J, Virtanen M, Vahtera J, Kivimaki M: Sleep disturbances as a predictor of cause-specific work disability and delayed return to work. Sleep 2010, 33:1323-1331.

5. Lallukka T, Haaramo P, Lahelma E, Rahkonen O: Sleep problems and disability retirement: a register-based follow-up study. Am J Epidemiol 2011, 173:871-881.

6. Rod NH, Vahtera J, Westerlund H, Kivimaki M, Zins M, Goldberg M, Lange T: Sleep disturbances and cause-specific mortality: results from the GAZEL cohort study. Am J Epidemiol 2011, 173:300-309.

7. Kohyama J: Sleep, serotonin, and suicide in Japan. J Physiol Anthropol 2011, 30:1-8. 
8. Kling RN, McLeod CB, Koehoorn M: Sleep problems and workplace injuries in Canada. Sleep 2010, 33:611-618.

9. Salminen S, Oksanen T, Vahtera J, Sallinen M, Harma M, Salo P, Virtanen M, Kivimaki M: Sleep disturbances as a predictor of occupational injuries among public sector workers. J Sleep Res 2010, 19:207-213.

10. Daley M, Morin CM, LeBlanc M, Gregoire JP, Savard J: The economic burden of insomnia: direct and indirect costs for individuals with insomnia syndrome, insomnia symptoms, and good sleepers. Sleep 2009, 32:55-64.

11. Rosekind MR, Gregory KB, Mallis MM, Brandt SL, Seal B, Lerner D: The cost of poor sleep: workplace productivity loss and associated costs. J Occup Environ Med 2010, 52:91-98.

12. Kessler RC, Berglund PA, Coulouvrat C, Hajak G, Roth T, Shahly V, Shillington AC, Stephenson JJ, Walsh JK: Insomnia and the performance of US workers: results from the America Insomnia Survey. Sleep 2011, 34:1161-1171.

13. Dawson D, McCulloch K: Managing fatigue: it's about sleep. Sleep Med Rev 2005, 9:365-380

14. Dorrian J, Sweeney M, Dawson D: Modeling fatigue-related truck accidents: prior sleep duration, recency and continuity. Sleep Biol Rhythms 2011, 9:3-11.

15. Dorrian J, Baulk SD, Dawson D: Work hours, workload, sleep and fatigue in Australian Rail Industry employees. Appl Ergon 2011, 42:202-209.

16. Thomas MJ, Ferguson SA: Prior sleep, prior wake, and crew performance during normal flight operations. Aviat Space Environ Med 2010, 81:665-670.

17. Ferguson SA, Paech GM, Dorrian J, Roach GD, Jay SM: Performance on a simple response time task: is sleep or work more important for miners? Appl Ergon 2011, 42:210-213.

18. Ogawa Y, Nakamura T, Takahashi M, Otsuka Y, Tamba H: [Report on prevention of occupational traffic accidents due to fatigue driving. Japan Ministry of Health, Labour and Welfare-commissioned research in 2006]. (in Japanese). Japan Ministry of Health, Labour and Welfare; 2006.

19. Belenky G, Wesensten NJ, Thorne DR, Thomas ML, Sing HC, Redmond DP, Russo MB, Balkin TJ: Patterns of performance degradation and restoration during sleep restriction and subsequent recovery: a sleep dose-response study. J Sleep Res 2003, 12:1-12.

20. van Dongen HP, Maislin G, Mullington JM, Dinges DF: The cumulative cost of additional wakefulness: dose-response effects on neurobehavioral functions and sleep physiology from chronic sleep restriction and total sleep deprivation. Sleep 2003, 26:117-126.

21. Rupp TL, Wesensten NJ, Bliese PD, Balkin TJ: Banking sleep: realization of benefits during subsequent sleep restriction and recovery. Sleep 2009, 32:311-321.

22. Dawson D, Reid K: Fatigue, alcohol and performance impairment. Nature 1997, 388:235

23. Takahashi M: The role of prescribed napping in sleep medicine. Sleep Med Rev 2003, 7:227-235.

24. Takeyama H, Kubo T, Itani T: The nighttime nap strategies for improving night shift work in workplace. Ind Health 2005, 43:24-29.

25. Milner CE, Cote KA: Benefits of napping in healthy adults: impact of nap length, time of day, age, and experience with napping. J Sleep Res 2009, 18:272-281.

26. Lovato N, Lack $L$ : The effects of napping on cognitive functioning. Prog Brain Res 2010, 185:155-166.

27. Waterhouse J, Atkinson G, Edwards B, Reilly T: The role of a short postlunch nap in improving cognitive, motor, and sprint performance in participants with partial sleep deprivation. J Sports Sci 2007, 25:1557-1566.

28. Lahl O, Wispel C, Willigens B, Pietrowsky R: An ultra short episode of sleep is sufficient to promote declarative memory performance. I Sleep Res 2008, 17:3-10

29. Ficca G, Axelsson J, Mollicone DJ, Muto V, Vitiello MV: Naps, cognition and performance. Sleep Med Rev 2010, 14:249-258

30. Lau H, Tucker MA, Fishbein W: Daytime napping: effects on human direct associative and relational memory. Neurobiol Learn Mem 2010, 93:554-560.

31. Naska A, Oikonomou E, Trichopoulou A, Psaltopoulou T, Trichopoulos D: Siesta in healthy adults and coronary mortality in the general population. Arch Intern Med 2007, 167:296-301

32. Vgontzas AN, Pejovic S, Zoumakis E, Lin HM, Bixler EO, Basta M, Fang J, Sarrigiannidis A, Chrousos GP: Daytime napping after a night of sleep loss decreases sleepiness, improves performance, and causes beneficial changes in cortisol and interleukin-6 secretion. Am J Physiol Endocrinol Metab 2007, 292:E253-261.

33. Faraut B, Boudjeltia KZ, Dyzma M, Rousseau A, David E, Stenuit P, Franck T, Van Antwerpen P, Vanhaeverbeek M, Kerkhofs M: Benefits of napping and an extended duration of recovery sleep on alertness and immune cells after acute sleep restriction. Brain Behav Immun 2011, 25:16-24.

34. Arora V, Dunphy C, Chang VY, Ahmad F, Humphrey HJ, Meltzer D: The effects of on-duty napping on intern sleep time and fatigue. Ann Intern Med 2006, 144:792-798.

35. Smith SS, Kilby S, Jorgensen G, Douglas JA: Napping and nightshift work: effects of a short nap on psychomotor vigilance and subjective sleepiness in health workers. Sleep Biol Rhythms 2007, 5:117-125.

36. Fallis WM, McMillan DE, Edwards MP: Napping during night shift: practices, preferences, and perceptions of critical care and emergency department nurses. Crit Care Nurse 2011, 31:e1-11.

37. Takahashi M, Iwakiri K, Sotoyama M, Hirata M, Hisanaga N: Musculoskeletal pain and night-shift naps in nursing home care workers. Occup Med (Lond) 2009, 59:197-200.

38. Roach GD, Darwent D, Sletten TL, Dawson D: Long-haul pilots use in-flight napping as a countermeasure to fatigue. Appl Ergon 2011, 42:214-218.

39. Signal TL, Gander PH, Anderson H, Brash S: Scheduled napping as a countermeasure to sleepiness in air traffic controllers. J Sleep Res 2009, 18:11-19.

40. Philip P, Taillard J, Moore N, Delord S, Valtat C, Sagaspe P, Bioulac B: The effects of coffee and napping on nighttime highway driving: a randomized trial. Ann Intern Med 2006, 144:785-791

41. Costa G, Haus E, Stevens R: Shift work and cancer - considerations on rationale, mechanisms, and epidemiology. Scand J Work Environ Health 2010, 36:163-179.

42. International Agency for Research on Cancer (IARC): IARC monographs on the evaluation of carcinogenic risks to humans. Volume 98, Painting, Firefighting, and Shiftwork Lyon: IARC; 2011.

43. Stevens RG, Blask DE, Brainard GC, Hansen J, Lockley SW, Provencio I, Rea MS, Reinlib L: Meeting report: the role of environmental lighting and circadian disruption in cancer and other diseases. Environ Health Perspect 2007, 115:1357-1362.

44. Blask DE, Hill SM, Dauchy RT, Xiang S, Yuan L, Duplessis T, Mao L, Dauchy E, Sauer LA: Circadian regulation of molecular, dietary, and metabolic signaling mechanisms of human breast cancer growth by the nocturnal melatonin signal and the consequences of its disruption by light at night. J Pineal Res 2011, 51:259-269.

45. Kubo T, Takahashi M, Takeyama H, Matsumoto S, Ebara T, Murata K, Tachi N, Itani T: How do the timing and length of a night-shift nap affect sleep inertia? Chronobiol Int 2010, 27:1031-1044

46. Åkerstedt T, Nilsson PM, Kecklund G: Sleep and recovery. In Research in occupational stress and well being, Volume 7: Current perspectives on jobstress recovery. Edited by: Sonnetag S, Perrewé PL, Ganster DC. Bingley, UK JAl Press; 2009:205-247.

47. Kubo T, Takahashi M, Sato T, Sasaki T, Oka T, Iwasaki K: Weekend sleep intervention for workers with habitually short sleep periods. Scand J Work Environ Health 2011, 37:418-426.

48. Taylor A, Wright HR, Lack LC: Sleeping-in on the weekend delays circadian phase and increases sleepiness the following week. Sleep Biol Rhythms 2008, 6:172-179.

49. Sallinen M, Kecklund G: Shift work, sleep, and sleepiness - differences between shift schedules and systems. Scand J Work Environ Health 2010, 36:121-133.

50. Karlson B, Eek F, Orbaek P, Osterberg K: Effects on sleep-related problems and self-reported health after a change of shift schedule. J Occup Health Psychol 2009, 14:97-109.

51. van Dongen HP, Belenky G: Individual differences in vulnerability to sleep loss in the work environment. Ind Health 2009, 47:518-526.

52. Saksvik IB, Bjorvatn B, Hetland H, Sandal GM, Pallesen S: Individual differences in tolerance to shift work-a systematic review. Sleep Med Rev 2011, 15:221-235.

53. Kubo T, Takahashi M, Tachi N, Takeyama H, Ebara T, Inoue T, Takanishi T, Murasaki Gl, Itani T: Characterizing recovery of sleep after four successive night shifts. Ind Health 2009, 47:527-532.

54. Van Dongen HP, Belenky G, Vila BJ: The efficacy of a restart break for recycling with optimal performance depends critically on circadian timing. Sleep 2011, 34:917-929. 
55. Knauth $\mathrm{P}$, Hornberger $\mathrm{S}$ : Preventive and compensatory measures for shift workers. Occup Med (London) 2003, 53:109-116.

56. European Union: Working Time Directive (2003/88/EC). Official J Eur Union 2003, , L299: 9-19.

57. Takahashi M, Tanigawa T, Tachibana N, Mutou K, Kage Y, Smith L, Iso H: Modifying effects of perceived adaptation to shift work on health, wellbeing, and alertness on the job among nuclear power plant operators. Ind Health 2005, 43:171-178.

58. Kantermann T, Juda M, Vetter C, Roenneberg T: Shift-work research: Where do we stand, where should we go? Sleep Biol Rhythms 2010, 8:95-105.

59. James FO, Cermakian N, Boivin DB: Circadian rhythms of melatonin, cortisol, and clock gene expression during simulated night shift work. Sleep 2007, 30:1427-1436.

60. Gamble KL, Motsinger-Reif AA, Hida A, Borsetti HM, Servick SV,

Ciarleglio CM, Robbins S, Hicks J, Carver K, Hamilton N, et al: Shift work in nurses: contribution of phenotypes and genotypes to adaptation. PLoS One 2011, 6:e18395.

61. van Dongen HP: Predicting sleep/wake behavior for model-based fatigue risk management. Sleep 2010, 33:144-145

62. Faraut B, Boudjeltia KZ, Vanhamme L, Kerkhofs M: Immune, inflammatory and cardiovascular consequences of sleep restriction and recovery. Sleep Med Rev 2012, 16:137-149.

63. Axelsson J, Sundelin T, Ingre M, Van Someren EJ, Olsson A, Lekander M: Beauty sleep: experimental study on the perceived health and attractiveness of sleep deprived people. BMJ 2010, 341:c6614.

64. Wagner U, Gais S, Haider H, Verleger R, Born J: Sleep inspires insight. Nature 2004, 427:352-355

doi:10.1186/1880-6805-31-6

Cite this article as: Takahashi: Prioritizing sleep for healthy work schedules. Journal of Physiological Anthropology 2012 31:6.

\section{Submit your next manuscript to BioMed Central and take full advantage of:}

- Convenient online submission

- Thorough peer review

- No space constraints or color figure charges

- Immediate publication on acceptance

- Inclusion in PubMed, CAS, Scopus and Google Scholar

- Research which is freely available for redistribution

Submit your manuscript at www.biomedcentral.com/submit 